\title{
Simulasi Jaringan Local Area Network Menggunakan Cisco Packet Tracer
}

\author{
alfin aswar ${ }^{1}$, yohana ${ }^{2}$ \\ (Program Studi Teknik Informatika Fakultas Ilmu Komputer Universitas Lancang Kuning) \\ Jl. Yos Sudarso Km 8 Rumbai, telp/fax. (0761)53108 \\ (Jl. Yos Sudarso KM. 8 Rumbai, Pekanbaru, Riau, telp. 0811753 2015) \\ e-mail: $\underline{1 \text { alfinaswar@gmail.com }},{ }^{2}$ yohana@gmail.com,
}

\begin{abstract}
A computer network is a system consisting of computers that are designed to be able to share resources (printers, CPUs), communicate (telephones, short messages), and can access information (websites). The purpose of a computer network is to be able to achieve its objectives, every part of a computer network can request and provide services (service). In almost all computer network applications Parties who request / receive services are called clients (clients) and those who provide / send services are called servers ( server). This design is called a client-server system. Networks are divided into 2 types based on their transmission media, namely: 1. wired network and 2. wireless network. Wired Network is a data transmission medium used in this network in the form of cables and wireless networks that do not use cable instead of using electromagnetic waves as the main transmission media.
\end{abstract}

Keywords:

network, wireless, computer, network security.

\section{Pendahuluan}

Seiring perkembangan modernisasi dewasa ini, pekerjaan manusia menjadi lebih rumit dan memiliki kerumitan tinggi dalam pekerjaannya.hal terpenting dakan perkembangan dan dalam penyelesaian dari berbagai masalah belakangan ini adalah bagaimana seorang memperoleh data akurat,fleksibel, dan mudah didapatkan.hal ini memicu manusia untuk membuat jaringan yang mampu menghubungkan sebuah komputer dengan komputer lain nya. Baik dalam lingkup area tertentu atau tertutup hingga yang lebih luas atau global.

2. Metode

Perkembangan teknologi informasi dan komunikasi (TIK) yang begitu pesat. Perkembangan teknologi informasi dan komunikasi memberi peluangan baru dalam penyelenggaraan pendidikan yang tidak hanya terbatas oleh ruang dan waktu(Guntoro, Costaner, and Sutejo 2017).Oleh karena itu Dalam simulasi ini menggunakan Software Cisco packet tracer yang memudahkan mahasiswa untuk memahami sebuah topologi jaringan.

\subsection{Hardware dan Software}

Hardware yang dibutuhkan untuk melakukan simulasi jaringan adalah : Processor AMD E1-6010 1.35 Ghz atau lebih tinggi,Ram 4GB,HDD 500GB, SSD 120 GB dan system operasi windows 764 bit Service Pack 1.

\section{Data dan Jaringan}

(Anon 2015) Keamanan jaringan adalah proses untuk melindungi sistem dalam jaringan dengan mendeteksi

penggunaan yang berhak dalam jaringan. Pengelolahan terhadap pengendalian keamanan jaringan dapat 
dilihat dari sisi pengelolahan resiko (risk management).

(Putra and Sumarudin 2014) SSH merupakan teknik keamanan data dengan key public yang di generate di sisi klien dan server. Hasil dari enkripsi yang dihasilkan cukup memberikan hasil enkripsi yang baik.Dengan tidak memberikan beban jaringan yang berat.

(Meutia 2015) Serangan terhadap keamanan IoT dapat mencakup serangan terhadap label RFID, jaringan komunikasi maupun pada privasi data. Untuk mencegah dan mengatasinya dibutuhkan mekanisme dan protokol keamanan

(Diansyah 2015) untuk mendapatkan sebuah keamanan jaringan computer maka diperlukan suatu tools yang dapat mendeteksi adanya suatu mekanisme serangan dari jaringan. Jenis serangan yang terjadi bias flooding ataupun syn flood.

(Sulaiman 2016)Salah satu faktor yang mempengaruhi kualitas dalam jaringan adalah network security atau keamanan jaringan, banyak teknik yang dapat dilakukan dalam meningkatkan keamanan jaringan, baik dengan membangun sistem firewall.

(Putra 2016) Host-based Intrusion Detection System (HIDS) yang dimana Aktivitas sebuah host jaringan

\subsection{Cisco Packet Tracer}

Cisco packet tracer adalah sebuah cross-platform visual simulasi alat yang dirancang oleh Cisco Systems yang memungkinkan pengguna untuk membuat topologi jaringan dan meniru modern jaringan computer melalui computer. Packet tracer membantu mahasiswa untuk memahami topologi dan desain sebuah jaringan.

(Mufadhol 2012)Cisco packet tracer dapat digunakan untuk simulasi yang mencerminkan arsitektur dan juga individual akan dipantau apakah terjadi sebuah percobaan serangan atau penyusupan ke dalamnya atau tidak. snort merupakan bagian dari IDS dan merupakan sebuah perangkat lunak open source.

(Arianto 2009)LAN adalah jaringan yang mengkoneksikan dua komputer atau lebih menggunakan sinyal radio, cocok untuk berbagi-pakai file, printer, atau akses internet.

(teorikomputer.com 2017)Jaringan LAN atau jaringan lokal berfungsi untuk menghubungkan beberapa komputer dalam satu lokasi agar bisa terhubung satu sama lain sehingga akan memudahkan pertukaran data dan mempercepat proses kerja.

(Febriadi and Putra 2019)Computerbased information systems are very influential in the world of work, as well as web-based information systems are used as a means of information enhancement.

(Febriadi and Zamsuri 2017)The office has some computers and other tools that are useful in saving electronic data. In fact, the data are still saved in available cupboards and it is not efficient for an important data that is analyzed for more than one time

model dari jaringan komputer pada sistem jaringan yang digunakan. Dengan menggunakan aplikasi cisco packet tracer, simulasi mengenai jaringan dapat dimanfaatkan menjadi informasi tentang keadaan koneksi komputer dalam suatu jaringan

(Systems Cisco 2010)the Cisco ${ }^{\circledR}$ Packet Tracer e-learning software was developed to help Networking Academy students gain practical 
networking technology skills in a rapidly changing environment.
(Frezzo, Behrens, and Mislevy 2009)Simulation environments make it possible for students to learn about and interact with complex systems

\section{Uji Coba}

Tujuan membuat jaringan LAN pada Cisco packet tracer ini adalah agar saya nantinya bisa mengimplementasikan membuat jaringan LAN menggunakan satu server dan setiap server tersebut dapat terkoneksi dengan server. Sehingga antara server dan client dapat saling berkomunikasi dan bertukar data. Setiap laptop akan diberikan konfigurasi ip address, ip address merupakan identitas sebuah komputer dalam jaringan internet. Dengan demikian, pemilik Server dapat mengetahui semua IP address yang Terhubung Ke server. Ip terbagi Menjadi 4 kelas 1. Kelas A 1-126, 2. Kelas B 128-191. Kelas C 192-223, Kelas B 224-239. Pada uji simulasi ini menggunakan ip kelas C. berikut daftar hardware dan software yang digunakan dalam uji coba ini beserta konfigurasi ip untuk server dan setiap laptop.

Hrdware dan Software

Alat

Laptop / Komputer Cisco Packet Tracer
Jumlah 1

1 Versi Terbaru

\section{Cisco Packet Tracer}

Alat

Jumlah

$\begin{array}{ll}\text { Server } & 1 \\ \text { Switch } & 1 \\ \text { Laptop } & 4\end{array}$

\begin{tabular}{cc}
\multicolumn{2}{c}{ Konfigurasi Cisco Packet Tracer } \\
Alat & IP / Gateway \\
\hline Server & 192.168 .10 .1 \\
Laptop 1 & $192.168 .10 .2 / 192.168 .10 .1$ \\
Laptop 2 & $192.168 .10 .3 / 192.168 .10 .1$ \\
Laptop 3 & $192.168 .10 .4 / 192.168 .10 .1$ \\
Laptop 4 & $192.168 .10 .5 / 192.168 .10 .1$ \\
\hline
\end{tabular}




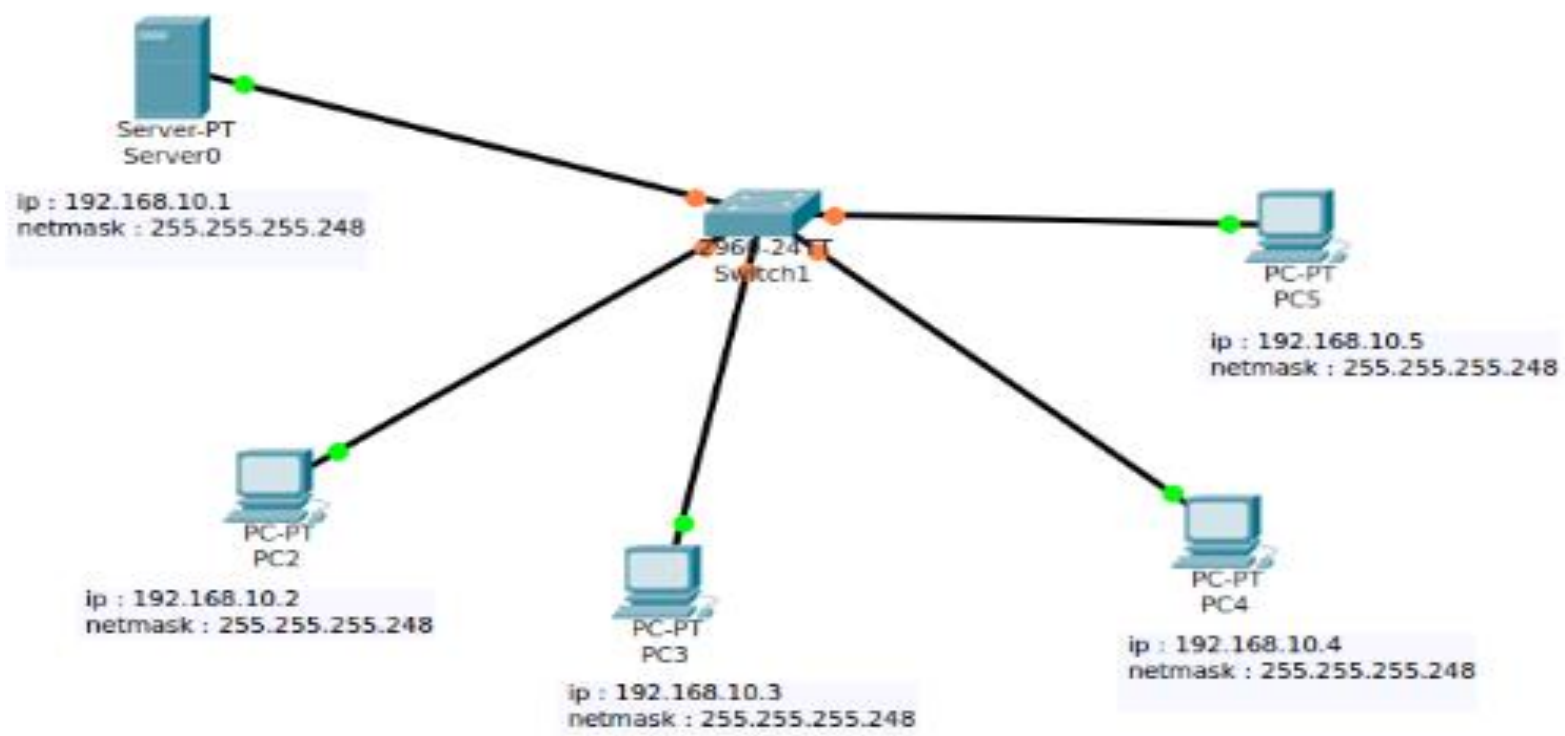

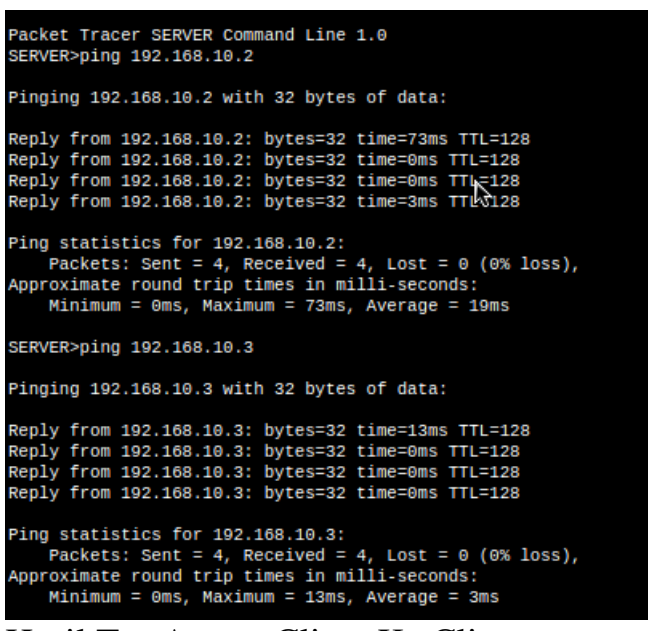

Hasil Tes Antara Client Ke Client

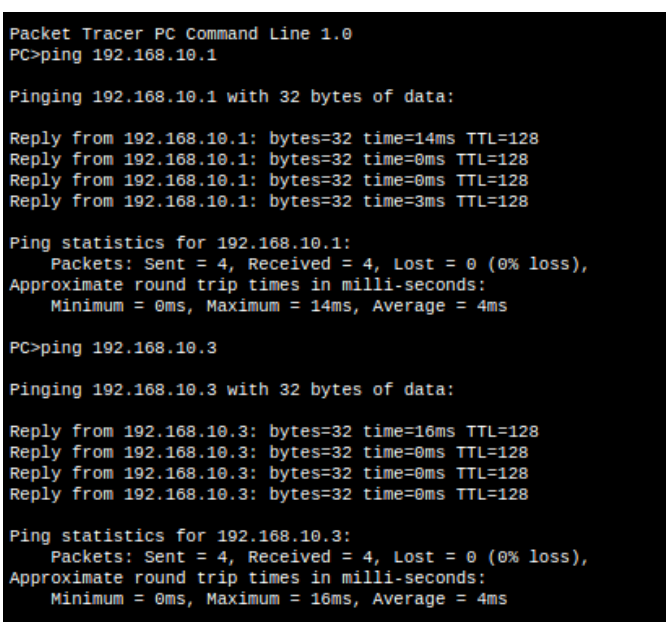

Hasil Tes Client ke Server

\section{Kesimpulan}

Kebutuhan informasi jaringan komputer begitu penting . Dengan menggunakan aplikasi software cisco packet tracer, simulasi data mengenai jaringan dapat dimanfaatkan menjadi informasi tentang keadaan koneksi suatu komputer dalam suatu jaringan, sehingga dapat digunakan untuk mendeteksi kerusakan jaringan komputer secara cepat, mudah, dan murah.

\section{Daftar Pustaka}

Anon. 2015. "Perancangan Dan Analisis Keamanan Jaringan Nirkabel Menggunakan Wireless Intrusion Detection System." E-JOURNAL TEKNIK ELEKTRO DAN KOMPUTER.

Arianto, Tri. 2009. "Implementasi Wireless Local Area Network Dalam RT / RW Net." ImplementasiWireless Local Area Network Dalam RT/RW Net.

Diansyah, Tengku Mohd. 2015. "Analisa Pencegahan Aktivitas Ilegal Didalam Jaringan Menggunakan Wireshark." Jurnal TIMES.

Febriadi, Bayu and Pandu Pratama Putra. 2019. "Rancang Bangun Aplikasi E-Register 
International Conference Berbasis Online Pada Universitas Lancang Kuning.” $J$ SAKTI (Jurnal Sains Komputer Dan Informatika).

Febriadi, Bayu and Ahmad Zamsuri. 2017. "Efektifitas Aplikasi RDBMS Sebagai Media Arsip Data Pada Kantor Kesehatan Pelabuhan Pekanbaru Berbasis Online." J-SAKTI (Jurnal Sains Komputer Dan Informatika).

Frezzo, Dennis C., John T. Behrens, and Robert J. Mislevy. 2009. “Activity Theory and Assessment Theory in the Design and Understanding of the Packet Tracer Ecosystem." International Journal of Learning and Media.

Guntoro, Guntoro, Loneli Costaner, and Sutejo Sutejo. 2017. "PELATIHAN SISTEM PEMBELAJARAN E-LEARNING PADA SEKOLAH MENENGAH KEJURUAN DWI SEJAHTERA PEKANBARU." Dinamisia : Jurnal Pengabdian Kepada Masyarakat.

Meutia, Ernita Dewi. 2015. "Internet of Things - Keamanan Dan Privasi." Seminar Nasional Dan Expo Teknik Elektro 2015.

Mufadhol, M. 2012. "SIMULASI JARINGAN KOMPUTER MENGGUNAKAN CISCO PACKET TRACER.” Jurnal Transformatika.

Putra, Pandu Pratama. 2016. "Pengembangan Sistem Keamanan Jaringan Menggunakan Rumusan Snort Rule (Hids) Untuk Mendeteksi Serangan Nmap.” Sains Dan Teknologi Informasi.

Putra, Willy Permana and Ahmad Sumarudin. 2014. "Keamanan Data Pada Jaringan Sensor Nirkabel Berbasis Linux Menggunakan SSH Protokol.” in IRWNS 2014. Sulaiman, Oris Krianto. 2016. "Analisis Sistem Keamanan Jaringan Dengan Menggunakan Switch Port Security." CESS (Journal of Computer Engineering, System and Science).

Systems Cisco. 2010. "Cisco Packet Tracer - Networking Academy." Cisco Press. teorikomputer.com. 2017. "Pengertian, Fungsi Dan Tujuan Jaringan LAN Pada Jaringan Komputer - Local Area Network | Tutorial Komputer." Http://Www.Teorikomputer.Com/2017/02/Pengertian-Fungsi-Dan-TujuanJaringan.Html. 